\title{
Through Open Innovation Concept Integrating Information Technology Resource into Instruction of School
}

\author{
James K.C. Chen \\ Department of Business Administration, Asia University, Taichung, in Taiwan \\ Benson S.S. Sun \\ Asia University
}

This study aims to construct a planning model for integrated information technology (IT) resource on instruction of school. The proposed model utilizes the open innovation concept to integrate IT into instruction resource allocation. The empirical case study demonstrates that loosening department resource constraints and utilizing De Novo programming technical assistance to gain the optimal resource allocation. Results shows the schools should have important priority for cultivating IT professional teachers of higher grades and teachers should share teaching materials to the others, and how to avoid the resources duplicated of different classes or grades.

\section{EXECUTIVE SUMMARY}

Through information technology (IT) assistant enhances teaching performance which is a popular approach of education. Notably, in the current e-era generation utilizes IT instructional tools that are engaged into teaching programs becomes the main trend of education. Additionally, there is a rich literature describing the integration of the instructional tools and teachers to access the instruction resources integrated conceptual model (Yasemin, 2007; Mueller, Wood, Willoughby, Ross, \& Specht, 2008). Unfortunately, less papers are based on open innovation concepts and the use of De Novo programming for planning instructional resources integration model.

This research discusses open innovation conceptual on school operations. It releases the boundary of human resources of teachers and IT instructional equipment in school, and utilizes De Novo programming (Zeleny, 1981, 1986) to integrate IT and human resources into instruction programs. This planning model can re-allocate the resources through De Novo programming technical and to achieve the goal with optimized solution. This IT resource allocation planning model is applicable on universal educational institutions.

\section{INTRODUCTION}

The widespread availability of digital learning resources in a variety of media formats offers the possibility to make a profound difference in education (Littlejohn, Falconer, \& McGill, 2008). Students use computers through the Internet to gain more efficient learning. Their learning approaches tend to be 
more diversified in nowadays. How to match the diversify learning development trend, information technology (IT) resources have been integrated as one of support instructional tools and would enable teachers to access the instruction resources integrated conceptual (Mueller, Wood, Willoughby, Ross, \& Specht, 2008). Moreover, teachers should be able to leverage sources and materials, adapt and contextualize them to suit individual needs through an efficient programming model. In particular, in the current e-era, the Internet allows students easy access to information and offers them stimulation on various kinds of knowledge. Teachers also have opportunities to change and adapt the curriculum in different ways or improve the quality of classroom activities by choosing appropriate technologies (Yasemin, 2007). IT instruction conveniently achieves instruction objectives, changes learning methods and improves teaching methods. IT did assistance on different kinds of teaching program for teachers (Sachsse \& Moir, 1999). The program of instruction planned to use computer aided instruction (CAI) for enhancing students' self-learning (Wang \& Chan, 1995). As teaching and training students' reading ability with CAI become the main issue in current instruction (Johnson, Perry, \& Shamir, 2010).

The issue of research innovation has attracted scholar attention and interest in the last century. Innovation varies in terms of products, services, processes and business practices (Christopherson, Kitson, \& Michie, 2008). In the field of education, innovation is considered a very important element of advanced teaching performance (Zhao, Pugh, Sheldon, \& Byers, 2002). Innovation encompasses a wide variety of related activities, from scientific discovery, technical and market research, manufacturing, and marketing, to the extent that these new ideas are demonstrated and applied to technology (Bromley, 2004). Open innovation means that valuable ideas can come from inside or outside the organization and can go to market from inside or outside of the organization as well (Chesbrough, 2003). Open innovation can be applied on knowledge integration. This new approach is developed from a different knowledge landscape, with a different logic about the sources and uses of ideas. How to collect external ideas transfer into internal ideas for an organization has become increasingly important. This study utilizes the open innovation concept to construct an efficient planning model on instruction resource allocation. The planning model thus constructed is applied to an elementary school of Taiwan for integration of K3-K6 education resources as an empirical case study.

In Taiwan, compulsory education comprises six years of elementary education and three years of junior high school education, covering a nine-year curriculum. In recent years, the Ministry of Education (MOE) has urged school administration 'to integrate IT resources into instruction', which is taken as an important indicator of instruction performance (Ministry of Education, 2008). Hence, schools of all levels devote great effort to the integration of IT hardware, software and teachers' IT knowledge into instruction development. Nevertheless, schools are caught between increasing demands for e-learning and constraints in education resources under the tight government budget. In face of such circumstances, resource allocation of a school has become more important. Proper resource allocation can enhance instruction performance, which in turn determines the education outcome. Indeed, an efficient planning model aids enterprises/schools in optimal resource allocation to achieve the aspiration levels of operational goal (Campi \& Bella, 1998).

This study utilizes De Novo programming (Zeleny, 1981, 1986) to integrate IT resources into instruction programs. It redesigns or reshapes given systems to achieve an aspiration/desired level (Zeleny, 1990). This approach establishes a resource allocation planning model for resource integration. Following the concept of open innovation, this work regards external ideas as internal ideas and attempts to achieve more efficient resource allocation through De Novo programming. As mentioned above, the planning model constructed is applied to resource allocation of an elementary school as a case study. Analysis results show that the planning model contributes to more efficient resource allocation on instruction, thus avoiding waste and enhancing teaching performance with minimal cost.

The remainder of this paper is organized as follows. Section 2 discusses related theories of resource allocation planning model. Section 3 details the construction of an efficient planning model for instruction resource allocation. Section 4 describes open innovation and illustrates an empirical case to demonstrate how the proposed resource allocation model helps integrate IT resources into instruction. Section 5 presents conclusions, implications, and recommendations. 


\section{THEORETICAL BACKGROUND}

This section explores the related theoretical background of resource allocation planning model in the literature.

\section{Resource Allocation with Project Management}

Previous studies have often explored resource allocation using the resource-based view (RBV) of firm organization (Barney, 1991; Wernerfelt, 1984). Holcomb and Hitt (2007) describe tangible or intangible assets owned or controlled by firms as resources, and organizational routines that allow firms to effectively integrate and use resources allocation to implement on their strategies planning. Resources have two key features: (1) they must enable the creation of organization's value; (2) this resource provide unique supporting that is can resist duplicative efforts from the competitors (Barney, 1991). A firm's competitiveness or operational performance always is dependence on their key resources it possesses (Collis, 1991).

Resource-based view of integration originated from the theory of the growth of the firm (Penrose, 1959). Barney (1991) puts forward a more contemporary interpretation of RBV, emphasizing the importance of resources in guiding firm activity, transaction cost and managing a firm's portfolio of capabilities as central to enhancing competitive advantage (Anderson \& Gatignon, 1986; Holcomb \& Hitt, 2007). The definition of RBV theory describes the resources as either tangible or intangible, and as both heterogeneous and imperfectly mobile among firms (Barney, 1991). RBV theory has been studied extensively in business strategy in the past decade and has become a popular explanation of performance heterogeneity at the firm level (Chimhanzi \& Morgan, 2005; Fahy, 2002). According to RBV theory, firms/schools seek complementary resource allocation to create synergies and acquire sustainable competitive advantages (Harrison, Hoskisson, \& Ireland, 1991). To respond quickly to a dynamic environment, firms/schools should consider constructing and extending limited resources to develop a capability for sustainable competitive advantage (Teece, Pisano, \& Shuen, 1997).

The pharmaceutical industry utilizes project management aspects of scheduling arranged and resource allocation on R\&D pipelines that is a practical approach to improving management performance (Varma, Pekny, Blau, \& Reklaitis, 2008). Project planning and scheduling arranged has become an important management tool for today's complex investment environment (Kolisch, 1996; Kolish \& Hartmann, 2006). Through project management can enhance resource allocation planning quality and help organizations upgrade their performance (Leiblein, 2003). An efficient planning model that can aid schools in achieving optimal instruction resource allocation and, consequently, better instruction outcome is not only desirable but necessary.

\section{Strategic Alliance Planning of Resource Allocation}

Integrating IT resources into instruction has become an important target in school. Moore and Benbasat (1991) suggest developing an instrument to help firms enhance their adoption of IT. They regard firms as resource bundles for strategic alliance, capabilities, and competencies that provide a distinct source of competitive heterogeneity (Barney, 1991; Hoskisson, Hitt, Wan, \& Yiu, 1999). Faced with insufficient resources, schools should on the one hand seek for more instruction resources to support day-by-day teaching and, on the other hand, utilize fully existing resources by reducing wasting and perhaps reallocating resources according to needs and goals. An efficient planning model would enhance the utilization of school resources and improve both teaching and learning performance. Although computers are powerful tools for improving instruction effectiveness, inappropriate usage and improper technology planning results in loss of time, energy and fiscal resources (Yasemin, 2007). Strategic alliance planning for integrating IT resources into instruction activity will enhance school instruction performance.

Competitive strategy is an important management issue. Scholars considered competitive strategy very useful for planning and increasing efficiency across organizations management (Kolish \& Hartmann, 2006; Miller \& Cardinal, 1994). Both comparative advantages in resources allocation and resource 
deployment contribute to enhance performance (Hunt, 2000). To achieve high performance of operational, the top managers should be provided a conspicuous goal of strategic direction (Hart \& Banbury, 1994). Strategic alliance planning is a tool of management in defining a company's future progression direction and developing a plan for its development in the future (Drakopoulos, 1999; Kolish \& Hartmann, 2006; Kumar, Maheshwari, \& Kumar, 2002; Lewis, 1989; Wainwright \& Waring 2004). Schools also can utilize strategy alliance planning to create much more add value of instruction. Integrating IT resources into instruction is one type of strategic alliances that can help schools improve teaching performance.

\section{De Novo Programming Approach to Resource Allocation}

The classical De Novo programming method proposed by Zeleny $(1981,1986,1990)$ is an effective approach in dealing with optimal design problems. Currently, system analysis and design have become important managerial and operational issues in many countries and regions around the world (Zhang, Huang, \& Zhang, 2009). The original idea of De Novo programming does not advocate production of individual or separate resources. Instead, instruction resources are related and not independent. In the real world, it is virtually impossible to optimize all criteria when confronting a situation. The concept of tradeoff then becomes useful when considering multiple criteria and when operating under limited resources. Zeleny (1995) regards trade-offs as properties of an inadequately designed system and can thus be eliminated through designing a better, preferably optimal, system. The De Novo programming approach can deal with an optimization problem involving multiple criteria. Hence, this approach is adopted in this study to construct the planning model for instruction resource integration that can be universally applied to schools for different countries.

\section{Open Innovation}

Open innovation has emerged as a new key theory in recent years. It is a novel model for organizing technological innovation in large R\&D intensive companies (Chesbrough, Anhaverbeke, \& West, 2006). According to open innovation model, firms can and should use both internal and external ideas, and access the markets through both internal and external paths when they advance their technology (Chesbrough, 2003). Open innovation offers systematic incentives and explores a wide range of internal and external sources for innovative opportunities, consciously integrating such exploration with firm's capabilities and resources, and broadly exploiting those opportunities through multiple channels (West $\&$ Gallagher, 2006). Open innovation has become increasingly important for both practice and theory. Organizations need shorter innovation cycles time and lower R\&D costs.

The managerial challenges of open innovation involve utilizing external knowledge, then identifying useful external knowledge, and integrating that knowledge with the firm. For example, new products have significant trade-offs between innovation speed, development costs, and competitive advantage in relying on external rather than internal learning (Kessler, Bierly, \& Gopalakrishnan, 2000). The open innovation phenomenon is reinforced by increasing globalization of research, technologies and innovation, new information and communication technologies, and potentials of new organizational forms and business models (Gassmann \& Enkel, 2004).

Chesbrough, Anhaverbeke and West (2006) show that the open innovation paradigm treats R\&D as an open system, in which valuable ideas come from inside or outside the company and go to market from inside or outside the firm (see Figure 1). This study combines the concepts of open innovation, strategic alliance and De Novo programming approach integrates school's resource application on instruction task. 


\section{FIGURE 1}

\section{THE OPEN INNOVATION PARADIGM}

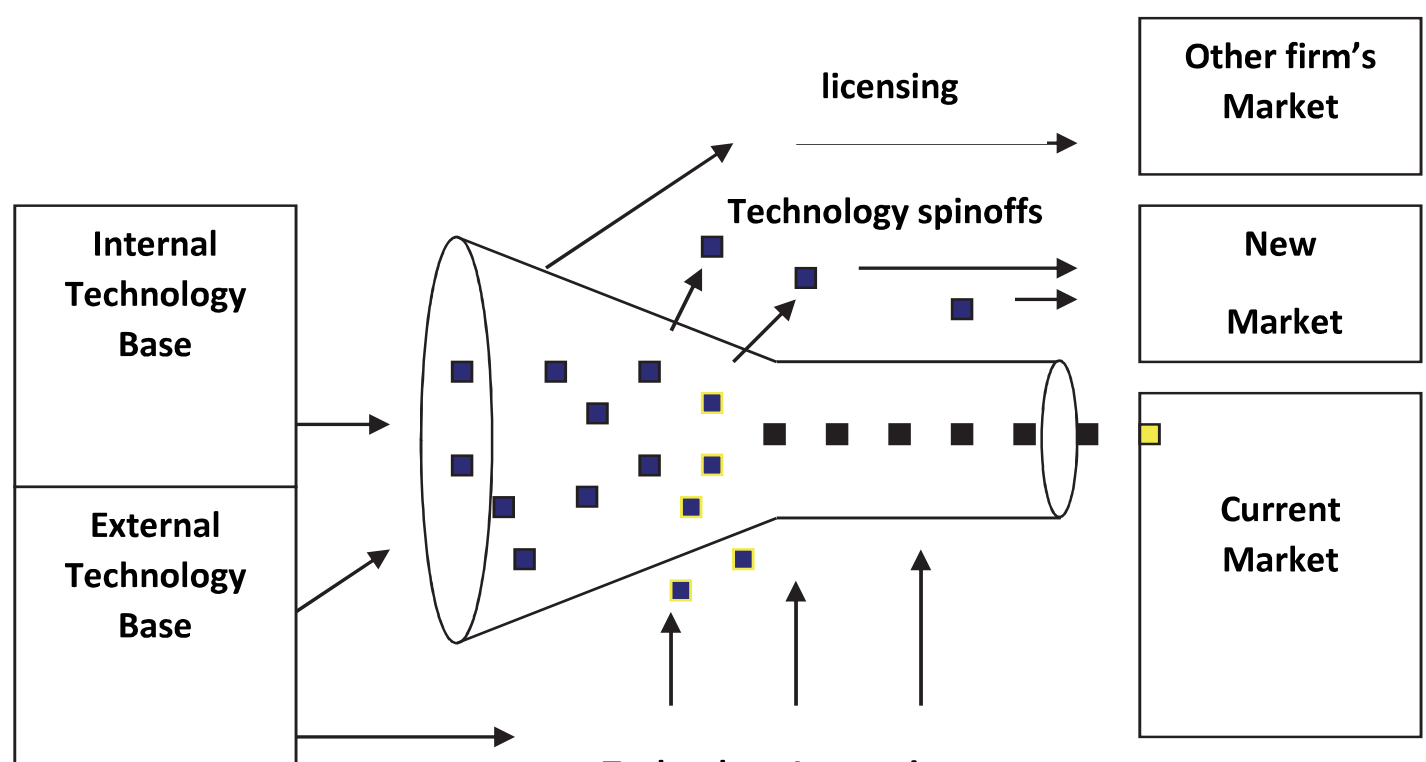

Technology Insourcing

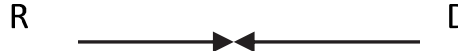

Sources from Chesbrough et al., 2006

\section{MODEL FORMULATION}

As seen in the above discussion, resource allocation plays a central role in instruction resource allocation and promotes sustainability efforts. Next section explores the construction of an efficient planning model for instruction resource allocation using De Novo programming.

\section{Instruction Resource Allocation}

The elementary Schools face many constraints including lack of teachers, IT resources and classroom space, which in turn affects the teaching effectiveness and student learning performance (Dawson, Pringle, \& Adams, 2003). Optimal resource allocation by mathematic programming thus becomes a key issue in instruction research. Mathematic programming distributes limited resources to competing activities to achieve optimal resource allocation. Linear programming is the most popular mathematic programming approach. Kantorovich and Koopmans (1976) develop linear programming and the general matrix formulation of linear programming, which can be described as follows.

\section{$\operatorname{Max} \boldsymbol{C x}$ \\ s.t. $\quad \boldsymbol{A x} \leq \boldsymbol{b}$ \\ $\boldsymbol{x} \geq 0$}

where both $\boldsymbol{C}=\boldsymbol{C}_{q \times n}$ and $\boldsymbol{A}=\boldsymbol{A}_{m \times n}$ are matrices, $\boldsymbol{b}=\left(b_{1}, \ldots, b_{m}\right)^{T} \in R^{m}$, and $\boldsymbol{x}=\left(x_{i}, \ldots, x_{j}, \ldots, x_{n}\right)^{T} \in R^{n}$.

Let the $k^{\text {th }}$ row of $C$ be denoted by $C^{k}=\left(c_{i}^{k}, \ldots, c_{j}^{k}, \ldots c_{n}^{k}\right) \in R^{n}$, so that $C^{k} x,(k=1, \ldots, q)$ is the $k^{\text {th }}$ criterion or objective function. This linear programming problem can be solved in several ways, which include using the simplex method or the interior-point algorithm that allocates limited resources 
optimally. Although mathematic programming provides a solution approach to the resource allocation problem, it is unreasonable to assume additivity when extending this approach to manage an alliance resource. This is because additivity presumes that all productive elements are independent and the total effects equal the summation of each individual effect. Such assumption is not valid when schools want to create synergies.

The concept of emerging mass customization has been proposed for solving the problem of element independence. Generally, a company can obtain profits in two ways. One is to increase unit revenue with higher unit cost through customizing, and the other is to reduce unit cost by economies of scale. With element independence, it is impossible to reduce unit cost and increase unit revenue simultaneously. Utilizing the concept of mass customization can release limited element independence. This study assumes that there exists a market alliance between companies $\mathrm{A}$ and $\mathrm{B}$ with $\pi_{A}$ and $\pi_{B}$ denoting their respective profits. The goal of a company is to maximize profits, and the feasible solutions are within the space surrounded by dotted lines shown in Figure 2. Compromise solutions are typically the best decision in traditional mathematic programming and they fall into $\mathrm{A} \cap \mathrm{B}$. Options contained in points $A, B$ and $C$, including the ideal point $C$, are unavailable options, which are caused by assuming linear programming additivity.

According to the assumption of additivity, combining alliance resources allows only $1+1=2$, rather than $1+1>2$. However, synergies are usually the reason or result of strategic alliances (Das \& Teng, 2000). In other words, traditional mathematic programming is rational and available when a firm has resource constraints that cannot be changed if it produces individually (Babic \& Pavic, 1996). However, the traditional approach is no longer suitable when redesigning or reshaping systems and this usually happens in strategic alliances.

This study utilizes De Novo programming to release limited element independence and to solve the problem of an optimal resource portfolio in strategic alliances to achieve the aspiration level.

FIGURE 2

\section{FEASIBLE OPTIONS OBTAINED USING LINEAR PROGRAMMING}
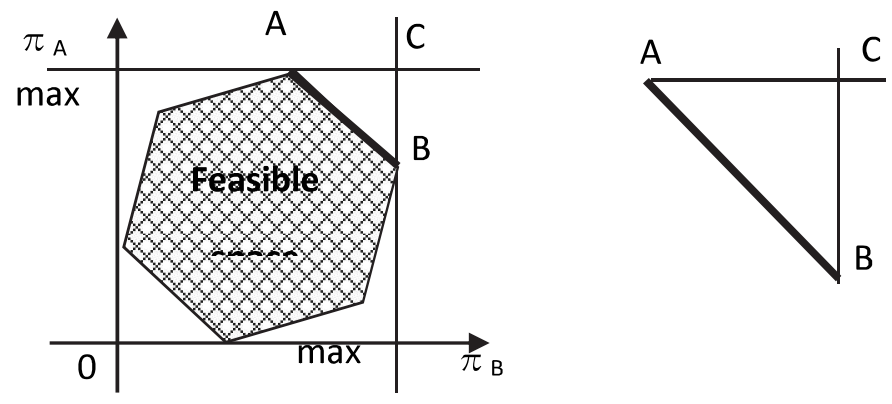

\section{De Novo Programming Approach of Strategic Alliances}

The De Novo programming approach can re-modify the systems to achieve an aspiration level of company/school operation. By releasing various constraints, the De Novo programming approach attempts to break limitations to achieve the desired solution. Through formation strategic alliance and resource allocation, the current work extends the De Novo programming approach to obtain an optimal solution (Chen \& Tzeng, 2009; Huang, Tzeng, \& Ong, 2005, 2006). The De Novo perspective combines transaction cost theory and Resource-Based View (RBV) to provide a holistic perspective for achieving an aspiration level (Grant, 1991). In this study, schools seek strategic alliance/resource allocation according to the instruction cost theory. If the minimum alliance cost lies between instruction cost and IT resource cost, the school should seek strategic alliance/resource allocation for instruction resources sharing. Here, we add strategic alliance cost (e.g., risk cost, negotiation and shared operation) to explain 
the formation of strategic alliance/resource allocation, and the rule of instruction cost theory can be modified as

if $\begin{gathered}\text { alliance } \\ \text { allocation }\end{gathered} \quad \cos t \leq \sum_{i=1}^{N}$ individual school's cost, then the school seeks $\begin{gathered}\text { alliance } \\ \text { allocation }\end{gathered}$.

From the RBV, schools seek resource allocation capabilities by allying with a partner to create synergies on instruction resources. The rule of the RBV can be modified as

if $\begin{gathered}\text { alliance } \\ \text { allocation }\end{gathered} \quad$ profit $\geq \sum_{i=1}^{N}$ individual school's profit, then the school seeks $\begin{gathered}\text { alliance } \\ \text { allocation }\end{gathered}$.

Now, we combine the instruction cost theory and the RBV into the De Novo perspective, if the school chooses only two different resources, and, for reallocation, the rule of resource allocation can be expressed as

if $E(S \cup T)-U\left(C_{S T}\right)>E(S)+E(T)-U\left(C_{S}\right)-U\left(C_{T}\right)$, then the school seeks resource allocation.

We can express a general formula as follows

if $E\left(S_{1} \cup S_{2} \ldots \cup S_{N}\right)-U\left(C_{\text {alliance cost }}\right) \geq \sum_{i=1}^{N}\left[E\left(S_{i}\right)-U\left(S_{i}\right)\right], \quad i=1,2, \ldots, N$,

where $E(\bullet)$ denotes the profit function, $U(\bullet)$ denotes the cost function, $C_{S}$ and $C_{T}$ denote the total instruction cost in $S$ and $T$, respectively, and $C_{S T}$ denotes the alliance/allocation cost between $S$ and $T$ The probability of $S$ and $T$ events seeking strategic alliance/resource allocation can be expressed, respectively as

$p(s)= \begin{cases}1, & \lambda E(S \cup T)-\theta U\left(C_{S T}\right)>E(S)-U\left(C_{S}\right) \\ 0, & \lambda E(S \cup T)-\theta U\left(C_{S T}\right)<E(S)-U\left(C_{S}\right)\end{cases}$

and

$p(\mathrm{~T})= \begin{cases}1, & (1-\lambda) E(S \cup T)-(1-\theta) U\left(C_{S T}\right)>E(T)-U\left(C_{T}\right) \\ 0, & (1-\lambda) E(S \cup T)-(1-\theta) U\left(C_{S T}\right)<E(T)-U\left(C_{T}\right),\end{cases}$

where $\lambda$ denotes the percentage of increasing alliance profit in $S$, and $\theta$ denotes the percentage of reducing alliance cost in $S$. Now, we can incorporate De Novo programming into the planning and the problem of resource allocation can be expressed as:

$\max E(S \cup T)-U\left(C_{S T}\right)$,

s.t $\quad w x \leq B, \quad x \geq 0$.

where $w=p \mathrm{~A}=\left(w_{1}, \ldots, w_{n}\right) \in R^{n}$, and $p=\left(p_{1}, \ldots, p_{m}\right) \in R^{m}$ and $B \in R$ present the unit price of resources and the total available budget, respectively. Then, the knapsack solution is

$x^{*}=\left[0, \ldots, B / C_{k}, \ldots, 0\right]^{T}$, 
where $c_{k} / c_{k}^{*}=\max _{j}\left(c_{j} / c_{j}^{*}\right)$

The optimal solution to (4) is given by (5) and

$b^{*}=A x^{*}$,

The final alliance/allocation profit $\left(\Psi\left(S^{*}\right)\right)$ in $S$ is

$\Psi\left(S^{*}\right)=i^{\prime} b^{*} U\left(-C_{S T}\right)$,

where $i$ is the identity column vector. According to equation (8), we can judge whether or not the school should seek strategic alliance/resource allocation by equations (2) and (3). Furthermore, using De Novo programming, we can easily achieve optimal resource allocation and create synergies between alliances.

The difference between traditional mathematic programming and De Novo programming lies in the ability of the De Novo programming approach to redefine its boundaries or constraints through system redesign, reconfiguration or reshaping (Zeleny, 1990). Figure 3 shows the difference in feasible options obtained using De Novo programming.

The greatest difference between Figures 2 and 3 is that the unavailable solutions are now made available through De Novo programming. In other words, the ideal point is now the optimal solution in strategic alliance/resource allocation for achieving the aspiration level.

FIGURE 3

FEASIBLE OPTIONS OBTAINED USING DE NOVO PROGRAMMING

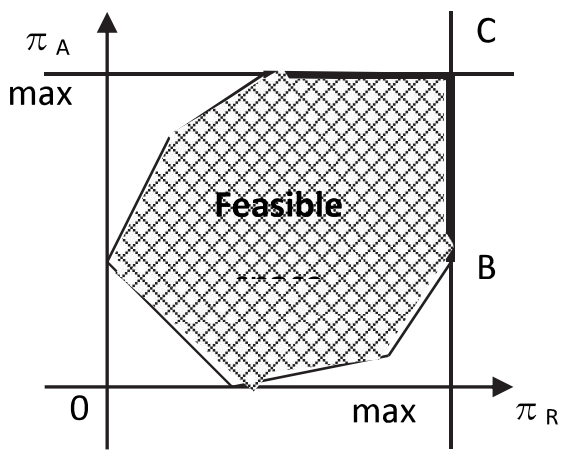

\section{EMPIRICAL STUDY}

It is commonly believed that integrating IT resources into instruction can enhance teaching performance, and such integration would require a complete planning model to ensure effectiveness. The proposed planning model is applied to an elementary school in Taiwan as a case study to examine its feasibility and performance.

\section{The Case School}

The elementary school taken for case study is located in central Taiwan. It was established in 1946 and offers education for Grades 1 to 6 . In 2009, the school had 33 teaching staff and six administrative staff. Among the total of 541 students, 379 were studying in Grades K3-K6.

IT resources of the case school were mainly of three types, namely hardware, software and human. Hardware resources included a computer classroom with 38 computers and a projection system, as well as one personal computer, one TV-video set, one DVD player and one CD player in each of the 19 classrooms. There were 39 computers for students (computer-student ratio of 1:13) and 21 computers for 
teachers. There were two notebook computers and a portable projection system for teaching activities. The school also had ink jet printers, laser printers with accessories and consumables for use by teachers. Teachers use Internet resources to print related materials for classroom instruction. Resource allocation planning helps teachers integrate IT resources into instruction and increases the use of IT in the classroom.

Software resources included School Free Soft 3.0 (SFS3) system, a freeware that contains various utilities for students and staff. Utilities provided through the website include the information desk, registration, grades and attendance for students, the registration office, the personnel office, accounting and stock for administrative staff and a question bank. Besides keeping periodic data about students, the system also analyzes various administrative procedures. The school also provides teaching materials, IT learning resources and teaching application software for teachers. Teachers can utilize these teaching materials, IT resources and software at any time.

Human resources included annual staff training funds from the ministry of education (MOE) for improving teaching effectiveness and efficiency and school learning activities. The MOE has offered a series of staff training courses on integrating IT into instruction for teachers. These courses can enhance the teachers' ability in integrating IT resources into instruction and help them obtain information from the Internet properly and safely.

\section{Integrating IT Resources into Instruction}

To develop a knowledge-based economy of the 21 st century, Taiwan proposed a "blueprint of technology education for middle and elementary school" (Ministry of Education, 2001) in 2001 to enhance national competitiveness as well as scientific and technical strength. Consequently, how to combine IT resources and human resources into instruction tasks is of great concern to education institutions. Technology is used in four ways, as a knowledge source, a data organizer, an information presenter, and a facilitator (Dawson et al., 2003; Pringle, Dawson, \& Marshall, 2002; Mann, Shakeshaft, Becker, \& Kottkamp, 1999). Most teachers, especially those who provide students with a stimulating teaching and learning environment, have been attracted by the powerful capacity of IT resources in collecting teaching materials from different information sources. Their desire to use IT is not only to teach their students how to access their teaching materials, but also to train their students to effectively explore information needed (Jang, 2008). IT usage as a learning instrument might lead to "improved students writing skills, enhanced cooperative learning, enhanced curriculum integration, greater application of learning style strategies, increased applications of cross-age tutoring, increased teacher communication, enhanced community relations and enhanced global learners" (Wang \& Chan, 1995; Whitehead, Jensen, \& Boschee, 2003).

Technology has become an integral part of the educational setting since its debut in the early 1980s and its use in the classroom has been met with mixed results. Teachers and researchers in the field of education have been given the responsibility of integrating technology into their curriculum (Plumm, 2008). Teachers have opportunities to change and adapt the curriculum in different ways or improve the quality of teaching activities by choosing the appropriate technology. However, using technology is not only about hardware and software alone. How to integrate technology into the others instruction program? It is very important issues one of the instruction tasks (Bennett \& Everhart, 2003).

Beetham (2002) emphasizes that in characterizing of IT resources that are effective in changing current instruction practice, it is appropriate to consider not only one of influence factor that impact on their teaching, but also enable teachers to gain a sense of ownership of the IT resources and incorporate IT resources into their instruction practice.

\section{Problem Descriptions}

Findings from the empirical case study reveal that the case school had devoted abundant resources to teaching activities, but the allocation of resources was far from appropriate. Integrating IT resources also involves proper allocation of hardware, software and human resources. The more properly the resources are allocated, the higher school performance would be. Timely provision of related resources by school 
administration to support instruction task is very important and has significant impact on teaching effectiveness. Hence, the construction of an optimal resource allocation model for resource integration is not only desirable but also necessary.

\section{Application of Resource Integration to Instruction}

In modern society, systems analysis and design have become important managerial and operational issues confronting many countries and regions in the world. It is an active process that seeks a portfolio of resource levels and optimizes the objective function by allocating a budget according to a resource price, where resource levels are considered as decision variables (Zeleny, 1990). In instruction resource planning systems, decision-makers are mainly concerned with determining availability of resources and/or identifying desired management approaches. Therefore, designing a sound instruction resource planning system for modeling various issues of instruction resources can facilitate decision-makers in effective and efficient allocation of instruction resources.

Computer technology continues to advance at an unprecedented pace in all aspects of our society. Systematic reviews of computer-assisted instruction suggest that there are small but positive effects beyond those found in traditional instruction (Blok, Oostdam, Otter, \& Overmaat, 2002). Studying availability of computers and Internet access has made computer technology a fixture in elementary and secondary schools, and integrate computers and teachers with limited integration (Mueller et al., 2008). In order to enhance technical competence of preservice teachers, technology instruction is provided by the inclusion of a separate technology course in many teaching education institutions (Wilson, 2003).

De Novo programming has previously been applied in different domains. The system thus designed can achieve ideal performance within a constant budget level. De Novo programming can shift the traditional approach of optimization, from optimization of a given instruction system, to the design of the optimal instruction system. With De Novo programming, schools can make strategy alliances with other partners and achieve efficient resource allocation through adjusting the instruction goal, re-modifying the instruction model, and justifying the target services.

\section{Empirical Case Study}

This section demonstrates the application of De Novo programming to instruction resource integration and utilizes a real case study for examining the feasibility and performance of the proposed planning model.

\section{Instruction Resource Allocation Model}

In the case study, IT was integrated into instruction at two grade levels: K3-4 and K5-6, in quantities and ,each consuming five different resources. The following summarizes the data shown in Table 1 . 
TABLE 1

MATERIAL RESOURCES REQUIRED BY GRADES K3-4 AND K5-6

\begin{tabular}{|c|c|c|c|c|c|}
\hline \multirow{2}{*}{ Unit price $\$$} & \multirow{2}{*}{\multicolumn{2}{|c|}{ Resources }} & \multicolumn{2}{|c|}{ Resources required } & \multirow{3}{*}{$\begin{array}{c}\begin{array}{c}\text { No. of units } \\
\text { (Resource portfolio) }\end{array} \\
30\end{array}$} \\
\hline & & & $x_{1}$ & $x_{2}$ & \\
\hline 260 & Human resources & Staff training & 5 & 12 & \\
\hline 100 & $\begin{array}{l}\text { Hardware } \\
\text { resources }\end{array}$ & $\begin{array}{c}\text { Computer and internet } \\
\text { equipment }\end{array}$ & 14 & 8 & 38 \\
\hline 40 & $\begin{array}{l}\text { Hardware } \\
\text { resources }\end{array}$ & Consumables & 6 & 6 & 15 \\
\hline 120 & Software resources & Teaching materials & 6 & 7 & 35 \\
\hline 30 & Software resources & Application software & 1 & 1 & 5 \\
\hline
\end{tabular}

The total cost of the given resource portfolio is calculated as follows:

$(260 * 30)+(100 * 38)+(40 * 15)+(120 * 35)+(30 * 5)=\$ 16650$

Unit costs of maintaining one unit of each of the two levels are

$x_{1}=(260 * 5)+(100 * 14)+(40 * 6)+(120 * 6)+(30 * 1)=\$ 3690$

$x_{2}=(260 * 12)+(100 * 8)+(40 * 6)+(120 * 7)+(30 * 1)=\$ 5030$

Expected profit margins (price-cost) are

$x_{1}=\$ 4090-\$ 3690=\$ 400 /$ unit

$x_{2}=\$ 5330-\$ 5030=\$ 300 /$ unit

Maximizing total value of function $\mathrm{f} 1$

$f_{1}=400 x_{1}+300 x_{2}$

Maximizing total quality index $\mathrm{f} 2$

$f_{2}=6 x_{1}+8 x_{2}$

The maximum profit/quality levels of two grades can be calculated by mathematical programming

$\max f_{1}=400 x_{1}+300 x_{2}$

$\max f_{2}=6 x_{1}+8 x_{2}$

s.t. $5 x_{1}+12 x_{2} \leq 30$

$14 x_{1}+8 x_{2} \leq 38$

$6 x_{1}+6 x_{2} \leq 15$

$6 x_{1}+7 x_{2} \leq 35$

$x_{1}+x_{2} \leq 5$

$x_{1}, x_{2} \geq 0$ 
Maximum $\mathrm{fl}$ in profit is

$\operatorname{Max} f_{1} \rightarrow x_{1}=1.6875, x_{2}=1.7968 f_{1}^{*}=400 \times 1.6875+300 \times 1.7968=1214.04$

Maximum $\mathrm{f} 2$ in total quality index is

$\operatorname{Max} f_{2} \rightarrow x_{1}=1.6875, x_{2}=1.7968 \quad f_{2}^{*}=6 \times 1.6875+8 \times 1.7968=24.4994$

Minimizing the total cost by considering the following constraints yields

$\min 3690 x_{1}+5030 x_{2}$

s.t. $f_{1}=400 x_{1}+300 x_{2} \geq 1214.04$

$f_{2}=6 x_{1}+8 x_{2} \geq 24.4994$

Maximum $\mathrm{fl}$ in profit is

$\operatorname{Max} f_{1} \rightarrow x_{1}=1.4445, x_{2}=2.1208 ; f_{1}^{*}=400 \times 1.4445+300 \times 2.1208=1214.04$

Maximum $\mathrm{f} 2$ in total quality index is

$\operatorname{Max} f_{2} \rightarrow x_{1}=1.4445, x_{2}=2.1208 ; f_{2}^{*}=6 \times 1.4445+8 \times 2.1208=25.6334$

The total cost of the newly designed system is calculated as follows

$(260 * 20.4)+(100 * 57.12)+(40 * 24.48)+(120 * 24.48)+(30 * 4.08)=\$ 15055.2<\$ 16650$

The new portfolio of resources obtained by the proposed planning model is as follows (see Table 2).

TABLE 2

NEW MATERIAL RESOUCES REQUIRED BY GRADES K3-4 AND K5-6

\begin{tabular}{|c|c|c|c|c|c|}
\hline \multirow{2}{*}{ Unit price $\$$} & \multirow{2}{*}{\multicolumn{2}{|c|}{ Resources }} & \multicolumn{2}{|c|}{ Resources required } & \multirow{3}{*}{$\begin{array}{c}\begin{array}{c}\text { No. of units } \\
\text { (Resource portfolio) }\end{array} \\
20.4\end{array}$} \\
\hline & & & $x_{1}$ & $x_{2}$ & \\
\hline 260 & Human resources & Staff training & 5 & 12 & \\
\hline 100 & $\begin{array}{l}\text { Hardware } \\
\text { resources }\end{array}$ & $\begin{array}{c}\text { Computer and internet } \\
\text { equipment }\end{array}$ & 14 & 8 & 57.12 \\
\hline 40 & $\begin{array}{l}\text { Hardware } \\
\text { resources }\end{array}$ & Consumables & 6 & 6 & 24.48 \\
\hline 120 & Software resources & Teaching materials & 6 & 7 & 24.48 \\
\hline 30 & Software resources & Application software & 1 & 1 & 4.08 \\
\hline
\end{tabular}

\section{Discussion}

To integrate IT resources into instruction, the De Novo programming approach re-modifies systems and adjusts the resource portfolio requirement for resource allocation planning. This planning achieves optimal resource allocation that enables the case school to reduce waste of resources and enhance school competitiveness. Some findings from the case study are worth attention.

\section{Human Resource Allocation}

The unit cost of human resources is higher than that of other resources. However, human resources are the most important resources in teaching activities. Higher grades require teachers with more 
professional skills; hence, schools should devote more human resources to grades K5-6, including more experienced and competent teachers proficient in subjects such as social studies, science, computer and foreign language. Teachers of higher grades need different methods for integrating different resources into their instruction. Schools need more well-trained teachers with the ability of professional teaching; hence this study suggest greater priority for enhancing IT knowledge and skills of K5-6 teachers.

\section{Software Resource allocation}

This study suggests greater flexibility in allocation of software resources. After redesigning software resource allocation planning using the De Novo programming approach, teachers can share their teaching materials and methods with other teachers. Teaching materials may be recycled and reused. Teachers can use the same teaching materials for different classes and grades. Schools should reduce waste of instruction resources, and devote more resources to areas in need to reach optimal resource allocation.

\section{CONCLUSIONS AND SUGGESTIONS}

Rapid developments in IT technology have driven educational institutions to train the 21 st-century generation to adapt to technological innovations (Yasemin, 2007). Schools explore and exploit the current instruction resource base to enhance their competitiveness. Adopting an efficient alliance/allocation planning model is the key element to achieving a school's instruction goals, especially as they relate to sustainability of resources. The present study develops a planning model from resource constraints and demonstrates that schools can construct an optimal instruction resource allocation planning model using De Novo programming. Instruction resource allocation through efficient planning not only achieves optimal resource allocation but also enhances teaching performance. In the case school, hardware, software and human IT resources are integrated into instruction. Results of the empirical case study suggest (1) cultivating competent subject teachers; and (2) teachers sharing teaching materials with each other and for different classes and grades. This study overcomes limitations in achieving the goal of optimal instruction resource allocation using De Novo programming and discusses how to achieve the best teaching performance under a changeable educational environment. The proposed resource allocation planning model is applicable not only to schools in Taiwan but also educational institutions of other countries.

Future researches can extend this study to analyze the impact of changes in hardware resources on software and human resources of instruction.

\section{REFERENCES}

Anderson, E., \& Gatignon, H. (1986). Modes of foreign entry: A transaction cost analysis and propositions. Journal of International Business studies, 17(3), 1-26.

Babic, Z., \& Pavic, I. (1996). Multicriterial production planning by De Novo programming approach. International Journal of Production Economics, 43(1), 59-66.

Barney, J.B. (1991). Firm resources and sustained competitive advantage. Journal of Management Science, 17(1), 99-120.

Beetham, H. (2002). Developing learning technology networks through shared representations of practice. Source Project Publication, PUB-OU-55.

Bennett, H., \& Everhart, N. (2003). Successful K-12 technology planning: ten essential elements. Teacher Librarian, 31(1), 22-26.

Blok, H., Oostdam, R., Otter, M.E., \& Overmaat, M. (2002). Computer-assisted instruction in support of beginning reading instruction: A review. Review of Educational Research, 72, 101-130.

Bromley, D.A. (2004). Technology policy. Technology in Society, 26, 455-468.

Campi, C., \& Bella, A.L. (1998). Analysis of the interaction between regional R\&D productivity and the investment strategic of multinational enterprises. Technological Forecasting and Social Change, 58(2), 241-249. 
Chen, J.K.C., \& Tzeng, G.H. (2009). Perspective strategic alliance and resource allocation in supply chain systems through the De Novo programming approach. International Journal Sustainable Strategic Management, 1(3), 320-339.

Chesbrough, H.W. (2003). Open innovation: The new imperative for creating and profiting from technology. Boston, MA: Harvard Business School Press.

Chesbrough, H., Anhaverbeke, W., \& West J., eds. (2006). Open innovation: Researching a new paradigm. Oxford University Press.

Chimhanzi, J., \& Morgan, R.E. (2005). Explanations from the marketing/human resources dyad for marketing strategy implementation effectiveness in service firms. Journal of Business Research, 58(6), 787-796.

Christopherson, S., Kitson, M., \& Michie, J. (2008). Innovation, networks and knowledge exchange. Cambridge Journal of Regions, Economy and Society. Oxford University Press for Cambridge Political Economy Society, 1(2), 165-173.

Collis, D.J. (1991). A resource-based analysis of global competition: The case of the bearings industry. Strategic Management Journal, 12(1), 49-68.

Das, T.K., \& Teng, B.S. (2000). A resource-based theory of strategic alliance. Journal of Management, 26(1), 31-61.

Dawson, K., Pringle, R., \& Adams, T.L. (2003). Providing links between technology integration, methods courses, and school-based field experiences: a curriculum-based and technology-enhanced microteaching. Journal of Computing in Teacher Education, 20(1), 41-47.

Drakopoulos, E. (1999). Enterprise network planning and design: methodology and application. Computer Communications, 22(4), 340-352.

Fahy, J. (2002). A resource-based analysis of sustainable competitive advantage in a global environment. International Business Review, 11(1), 57-78.

Gassmann, O., \& Enkel, E. (2004). Towards a theory of open innovation: Three core process archetypes. R\&D Management Conference (RADMA) (Lisbon, Portugal).

Grant, R. M. (1991). The resource-based theory competitive advantage: implications for strategy formulation. California Management Review, 33(3), 114-135.

Hart, S., \& Banbury, C. (1994). How strategy-making processes can make a difference. Strategic Management Journal, 15(4), 251-269.

Harrison, M.A., Hoskisson, R.E., \& Ireland, D. (1991). Synergies and post acquisition performance: Differences versus similarities in resource allocations. Journal of Management, 17(1), 173-190.

Holcomb, T.R., \& Hitt, M.A. (2007). Toward a model of strategic outsourcing. Journal of Operations Management, 25(2), 464-481.

Hoskisson, R.E., Hitt, M.A., Wan,. W.P., \& Yiu, D. (1999). Theory and research in strategic management: Swings of a pendulum. Journal of Management, 25(3), 417-456.

Huang, J.J., Tzeng, G.H., \& Ong, C.S. (2005). Motivation and resource-allocation for strategic alliances through the De Novo perspective. Mathematical and Computer Modeling, 41(6-7), 711-721.

Huang, J.J., Tzeng, G.H., \& Ong, C.S. (2006). Choosing best alliance partners and allocating optimal alliance resource using the fuzzy multi-objective dummy programming model. Journal of the Operational Research Society, 57, 1216-1223.

Hunt, S.D. (2000). A general theory of competition. Thousand Oaks, CA: Sage.

Jang, S.J. (2008). The effects of integrating technology, observation and writing into a teacher education method course. Computers \& Education, 50, 853-865.

Johnson, E.P., Perry, J., \& Shamir, H. (2010). Variability in reading ability gains as a function of computer-assisted instruction method of presentation. Computers \& Education, 55(1), 209-217

Kantorovich, L.V., \& Koopmans, T.C. (1976). Problems of application of optimization methods in industry. Federation of Swedish Industry, Sweden.

Kessler, E.H., Bierly, P.E., \& Gopalakrishnan, S.S. (2000). Internal vs. external learning in new product development: effects of speed, costs and competitive advantage. R\&D Management, 30(3), 213224. 
Kolisch, R. (1996). Efficient priority rules for the resource-constrained project scheduling problem. Journal of Operation management, 14(1), 179-192.

Kolish, R., \& Hartmann, S. (2006). Experimental investigation of heuristics for resource-constrained project scheduling: An update. European Journal of Operational Resource, 174(1), 23-37.

Kumar, V., Maheshwari, B., \& Kumar, U. (2002). ERP systems implementation: Best practices in Canadian government organizations. Government Information Quarterly, 19(2), 147-172.

Leiblein, M.J. (2003). The choice of organization governance form and performance: Predictions from transaction cost, resource-based, and real options theories. Journal of Management, 29(6), 973961.

Lewis, W.R. (1989). Strategic planning. Hospital Material Management Quarterly, 10(4), 57-63.

Littlejohn, A., Falconer, I., \& McGill, L. (2008). Characterizing effective e-Learning resources. Computers \& Education, 50(3), 757-771.

Mann, D., Shakeshaft, C., Becker, J., \& Kottkamp, R. (1999). West Virginia story: Achievement gains from a statewide comprehensive instructional technology program. Santa Monica. CA: Milken Exchange on Educational Technology.

Miller, C.C., \& Cardinal, L.B. (1994). Strategic planning and firm performance: a synthesis of more than two decades of research. Academy of Management Journal, 37(6), 1649-1665.

Mueller, J., Wood, E., Willoughby, T., Ross, C. \& Specht, J. (2008). Identifying discriminating variables between teachers who fully integrate computers and teachers with limited integration. Computer \& Education, 51(4), 1523-1537.

Ministry of Education (2001). The blueprint of the technology education for middle and elementary school. Taipei: Ministry of Education.

Ministry of Education (2008). Taiwan MOE's White paper for ICT in K-12 Education. Taipei: Ministry of Education.

Moore, G., \& Benbasat, I. (1991). Development of an instrument to measure the perceptions of adopting and information technology innovation. Information Systems Research, 2(3), 192-222.

Penrose, E. (1959). The Theory of the Growth of the Firm. NY: Wiley and Sons.

Plumm, K.M. (2008). Technology in the classroom: Burning the bridges to the gaps in gender-biased education? Computers \& Education, 50(3), 1052-1068.

Pringle, R., Dawson, K., \& Marshall, S. (2002). Technology, science, and pre-service teachers: Creating a culture of technology-savvy elementary teachers. Paper presented at the Society for Information Technology and Teacher Education, Nashville, TN.

Sachsse, M., \& Moir, A. (1999). Strategic asset management for tertiary institutions. Programming on Educational Building, PEB Papers. (ERIC Document Reproduction Service No. ED439592)

Teece, D.J., Pisano, G., \& Shuen, A. (1997). Dynamic capabilities and strategic management. Strategic Management Journal, 18(7), 509-533.

Varma, V.A., Pekny, J.F., Blau, G.E., \& Reklaitis, G.V. (2008). A framework for addressing stochastic and combinatorial aspects of scheduling and resource allocation in pharmaceutical R\&D pipelines. Computers and Chemical Engineering, 32, 1000-1015.

Wainwright, D., \& Waring, T. (2004). Three domains for implementing integrated IS: Redressing the balance between technology, strategic and organizational analysis. International Journal of Information Management, 24(4), 329-346.

Wang, P., \& Chan, P.S. (1995). Advantages, disadvantages, facilitators, and inhibitors of computer-aided instruction in Singapore's secondary schools. Computers \& Education, 25(3), 151-162.

Wernerfelt, B. (1984). A resource-based view of the firm. Strategic Management Journal, 5(2), 171-180.

West, J., \& Gallagher, S. (2006). Challenges of open innovation: The paradox of firm investment in opensource software. R\&D Management, 36(3), 319-331.

Whitehead, B.M., Jensen, D.F.N., \& Boschee, F. (2003). Planning for technology: A guide for school administrators. technology coordinators, and curriculum leaders. USA: Corwin Press. 
Wilson, E.K. (2003). Preservice secondary social studies teachers and technology integration: what do they think and do in their field experiences. Journal of Computing in Teacher Education, 20(1), 29-39.

Yasemin, G. (2007). Technology planning: A roadmap to successful technology integration in schools. Computers \& Education, 49, 943-956.

Zeleny, M. (1981). A case study in multiple objective design: De Novo programming. In: Multiple Criteria Analysis. Operational Methods, 1, 37-52.

Zeleny, M. (1986). Optimal system design with multiple criteria: De Novo programming approach. Engineering Costs and Production Economics, 10(1), 89-95.

Zeleny, M. (1990). Optimal given system vs. designing optimal system: the De Novo programming approach. International Journal of General System, 17(3), 295-307.

Zeleny, M. (1995). Trade-offs free management via De Novo programming. International Journal Operations and Quantitative Management, 1(1), 3-13.

Zhang, Y.M., Huang, G.H., \& Zhang, X.D. (2009). Inexact de Novo programming for water resources systems planning. European Journal of Operational Research, 199(2), 531-541.

Zhao, Y., Pugh, K., Sheldon, S., \& Byers, J.L. (2002). Conditions for classroom technology innovations. Teachers College Record, 104(3), 482-515. 